\title{
Quando os discursos transformam e transtornam: uma abordagem psicossocial das práticas alimentares sobre corpos femininos
}

\author{
When discourses transform and disorder: a psychosocial approach to food practices on female bo- \\ dies
}

\author{
Natália de Souza Alves Ferreira ${ }^{\dagger *}$, Rafaela Barbosa de Sá ${ }^{\prime}$, Paulo Cesar Toledo de Almeida \\ Como citar esse artigo. FERREIRA, \\ Resumo
} N.S.A.; DE SÁ, R.B.; DE ALMEIDA, P.C.T. Quando os discursos transformam e transtornam: uma abordagem psicossocial das práticas alimentares sobre corpos femininos. Revista Mosaico, v.11, n.1, p. 78-82, 2020.

\begin{abstract}
O presente artigo tem como objetivo identificar como os discursos sociais afetam o corpo e influenciam nas práticas alimentares do público feminino. Através de revisão bibliográfica de artigos científicos e tendo como base a autora Naomi Wolf foi discutido como o corpo, principalmente das mulheres, é alvo de práticas de controle que acarretam na disfuncionalidade da ingestão de alimentos e na insatisfação corporal, dando início aos transtornos alimentares.

Palavras-chave: Corpo; Transtornos alimentares; Padrão de beleza.
\end{abstract}

\section{Introdução}

O presente artigo elabora algumas discussões visando identificar os discursos sociais que perpassam e afetam o corpo e influenciam nas práticas alimentares do público feminino, percebendo que tais narrativas podem potencializar o desenvolvimento de transtornos alimentares em mulheres. Por meio de uma revisão bibliográfica e tendo como base principal a autora Naomi Wolf (2019), será explicitado primeiramente o corpo como um produto sociocultural.

Sendo o corpo o instrumento principal do humano de expressar seus afetos, é possível entender, passando pela arte, pela filosofia até aos estudos médicos, suas diferentes representações. Por conta disso, torna-se também objeto fundamental para coerção social, através de discursos e práticas normativas. Quando se é um corpo feminino tais práticas são ainda mais incisivas, principalmente na questão estética, fazendo com que as mulheres busquem um padrão de beleza inalcançável o que produz um relacionamento disfuncional com a comida.

Os efeitos dessas práticas podem ser percebidos por meio dos transtornos alimentares. Aqui serão discutidos transtornos como a bulimia e a anorexia, suas definições e como se manifestam no público feminino. Estes são, principalmente, caracterizados por dietas restritivas, medo mórbido de engordar, uso de medicamentos para emagrecimento e atividades físicas exaustivas. Todos esses métodos são largamente fomentados pela sociedade e mídia, ao mesmo tempo em que promovem produtos excessivamente calóricos.

A partir do movimento feminista houve várias conquistas de direitos, isso fez com que o papel da mulher na sociedade mudasse colocando-a em lugares antes ocupados apenas por homens. Em resposta a esse movimento surgem padrões corporais como uma nova maneira de submeter a mulher ao domínio masculino. Com isso é visível que a imposição de tais métodos sobre as mulheres não se trata apenas de uma relação estética, mas também de controle sobre seu comportamento.

\section{O corpo}

O corpo é um dos alvos preferidos das práticas de controle. Desde suas representações em paredes, a que temos acesso através da arte rupestre, o corpo é virtualizado e investido de uma imagem potente. Dos

\footnotetext{
Afiliação dos autores:

${ }^{\dagger}$ Discente do curso de Psicologia, Universidade de Vassouras, Vassouras, Rio de Janeiro, Brasi ${ }^{\star}$ Bacharel em Engenharia Ambiental e Sanitária pela Universidade de Vassouras, Vassouras, Brasil.

* Psicólogo, mestre em Psicologia Social pelo PPGPS-UERJ, docente do Curso de Psicologia da Universidade de Vassouras, Vassouras, Rio de Janeiro, Brasil

* Email de correspondencia: almeida.pct@gmail.com
} 
desenhos nas cavernas até as imagens fragmentárias das tomografias de última geração que servem para as mais variadas intervenções contemporâneas, o corpo é trajetória, ponto de partida e de chegada (LÉVY, 1996).

Na filosofia, não é diferente. Desde os primeiros atomistas, há notícia de uma atenção especial ao corpo. O Clinâmen, conceito que Lucrécio forja a partir do atomismo de Epicuro, é o declínio de corpos que se encontram e se modificam mutuamente. Tal discussão é seminal e se rebaterá na Ética de Espinosa (2002), que tipifica os encontros de corpos em bons ou maus. Os efeitos dessa filosofia são fortes e ecoam no conceito de Corpo sem Órgãos ( $\mathrm{CsO})$, tomado de Antonin Artaud por Deleuze e Guattari, que o ampliam e o experimentam até o ponto de torná-lo um não-conceito (DELEUZE; GUATTARI, 1999). Para Michel Foucault (2009), o corpo disciplinado é efeito de técnicas de poder.

Corpo é razão para toda sorte de campo de conhecimento e experiência. No teatro, Artaud tinha uma questão insolúvel com o corpo e sua desconstrução pelo adoecimento (1988). Na literatura, Edgar Allan Poe toma o corpo como imagem do terror (2018). No cinema, Luís Buñuel (UM CÃO ANDALUZ, 1929) retalha um corpo surreal, com a explosão de um olho, à qual é impossível a indiferença.

É a partir do corpo que se afeta e é afetado. É local onde conexões são feitas. É tempo de vivências. Portanto, o corpo é tudo aquilo que permite ao ser humano ser o que ele é e o que foi construído dele. Em termos políticos, há discursos sobre o corpo que o torna palco de exercício de poder à medida que se descreve, classifica, identifica e diferencia. Desse modo, esses discursos, tomados como verdade, definem os espaços sociais nos quais corpos serão incluídos e, por conseguinte, excluídos (ANDRADE, 2003).

Por todas as manifestações humanas, o corpo se faz presente, como alvo de práticas. Como tais, estas produzem certos efeitos. Neste artigo, a abordagem se dá em relação a um corpo específico - o corpo feminino - e de um conjunto de práticas também delimitado as práticas em torno da alimentação. Quais seriam os efeitos dessas práticas nesses corpos?

\section{Os transtornos alimentares}

Os transtornos alimentares são marcados por uma desordem persistente no comportamento alimentar que gera um consumo ou uma absorção alterada de alimentos que causam sofrimento físico e psicológico (DSM - V, 2014). De acordo com dados do Ministério da Educação (BRASIL, 2019), setenta milhões de pessoas sofrem com esses transtornos mundialmente, o que os torna uma problemática pertinente e urgente no sentido da busca por uma compreensão de seu funcionamento e estratégias de enfrentamento, no que o presente texto pretende contribuir.

Para Oliveira e Hutz (2010), os transtornos alimentares são caracterizados por um medo exagerado de engordar e por um excesso de preocupação com a forma corporal e o peso. Além disso, há uma recusa em se alimentar que leva a uma perda de peso progressiva ou uma ingestão exacerbada de alimentos seguida de uso de laxantes e diuréticos. As autoras os consideram patologias graves, com altos índices de letalidade e que provocam sofrimento físico, emocional e social. Dentre os diversos transtornos alimentares, este trabalho enfoca a bulimia e a anorexia.

Hay (2002), em seu levantamento sobre ambos os transtornos, fornece uma avaliação do desenvolvimento dos estudos epidemiológicos, desde a incidência e a prevalência, até estudos comunitários, passando por estudos de caso-controle. Para a autora, a epidemiologia analítica é um instrumento potente para levantar e responder interrogações importantes sobre a natureza e os determinantes da bulimia e da anorexia.

A bulimia nervosa pode ser caracterizada pelo consumo compulsivo e rápido de uma grande quantidade de alimento, com pouco ou nenhum prazer, seguido de métodos compensatórios para evitar o ganho de peso e pelo medo exagerado de engordar (CORDÁS; CLAUDINO, 2002).

De acordo com o DSM - V (2014), a bulimia também se caracteriza por três aspectos essenciais. $\mathrm{O}$ primeiro aspecto são os episódios recorrentes de compulsão alimentar. Esses episódios são definidos como a ingestão, em um determinado limite de tempo, de uma quantidade de alimento maior que a maioria das pessoas na mesma situação. É acompanhada por uma sensação de perda de controle. O segundo aspecto são os comportamentos inapropriados para evitar o ganho de peso. Vômitos autoinduzidos, uso abusivo de diuréticos e laxantes, excesso de exercício físico e períodos de restrição alimentar são alguns dos comportamentos compensatórios. No levantamento feito por Cordás e Claudino (2002), chegou-se a 95\% dos pacientes com bulimia nervosa utilizando o vômito autoinduzido. $\mathrm{O}$ terceiro aspecto é a autoavaliação indevidamente influenciada pela forma e pelo peso corporal.

O sintoma principal desse transtorno é a compulsão alimentar que costuma aparecer em decorrência de uma dieta restritiva com o intuito de perder peso (APPOLINÁRIO; CLAUDINO, 2000). Dietas restritivas apresentam grande influência no desenvolvimento da bulimia. A dieta e a obesidade, embora sejam relevantes na etiologia da anorexia nervosa e do transtorno compulsivo alimentar periódico (TCAP), são mais importantes no desenvolvimento de bulimia nervosa (MORGAN et al., 2002). Segundo Wolf (2019), a restrição alimentícia provoca tamanho estresse que tal hábito pode ser promotor de transtornos alimentares. 
Ainda vale ressaltar que os episódios de purgação ocorrem às escondidas em sua maioria e trazem ao sujeito sentimentos de intensa culpa, vergonha e desejos de autopunição. (APPOLINÁRIO; CLAUDINO, 2000)

A bulimia tem maior incidência em jovens do sexo feminino. Segundo Appolinário e Claudino (2000), a bulimia está presente entre $1,1 \%$ a $4,2 \%$ das mulheres. Já Oliveira e Hurtz (2010) relatam que o número é de $1 \%$ a $3 \%$. No DSM - V (2014) a prevalência é de $1 \%$ a $1,5 \%$. Bastante diferente da anorexia nervosa, na qual há uma perda progressiva de peso, na bulimia, o indivíduo mantém o peso normal ou tem uma perda de peso pouco expressiva. (DSM-V, 2014).

A anorexia pode ser definida como a restrição voluntária de ingestão de alimentos, pelo medo mórbido de engordar, apesar de estar bem abaixo do peso, e por uma visão distorcida de seu próprio corpo (DSM-V, 2014). Além disso, também pode ser descrita por uma perda de peso exorbitante que aflige, majoritariamente, mulheres jovens. (CORDÁS; CLAUDINO, 2002).

Esse transtorno pode se manifestar em dois tipos, o com restrição alimentar e com compulsão alimentar. $\mathrm{Na}$ anorexia com restrição alimentar há uma redução severa na ingesta alimentar. Isso acontece de diversas maneiras, como controlar certos tipos de alimentos, contar calorias em todas as refeições ou também com o extremo uso de regras para se alimentar. Já no tipo com compulsão alimentar, também existe uma redução severa na forma de consumir alimentos, entretanto com episódios de compulsão alimentar. Esse tipo é caracterizado por uma ingestão exacerbada de alimentos seguidos de métodos compensatórios como vômito e uso de laxante. (DSM-V, 2014).

De acordo com Appolinário e Claudino (2000), a anorexia ocorre em $0,28 \%$ de forma pontual e entre $0,3 \%$ e $3,7 \%$ do público feminino de forma oscilante ao longo da vida. Os autores ainda afirmam que os picos de incidências são aos 14 e aos 17 anos. Já Oliveira e Hurtz (2010), relatam que a incidência desse transtorno entre jovens mulheres é de $0,5 \%$ a $1 \%$, mas que esses números são questionáveis porque apenas os casos graves chegam aos médicos.

Entretanto, se a anorexia for definida como medo compulsivo do alimento e uma fixação nele, talvez a maioria das mulheres ocidentais, hoje, vinte anos após o início da reação do sistema, possa ser chamada de anoréxica mental. (WOLF, 2019, p.267)

Os transtornos alimentares apresentam a maior taxa de mortalidade, sendo esta $20 \%$ a mais entre os demais transtornos mentais, levando à morte basicamente por desnutrição, parada cardiorrespiratória e suicídio (ANDRADE; BOSI, 2003). Wolf (2019) reforça esse pensamento afirmando que de $5 \%$ a $15 \%$ das pacientes hospitalizadas com anorexia morrem durante o tratamento.
São inúmeros os fatores que possibilitam o desenvolvimento de tais transtornos. Esses fatores são chamados de predisponentes, precipitantes e mantenedores. Os fatores predisponentes propiciam o surgimento da doença através de questões individuais, familiares/hereditários e socioculturais. Os precipitantes são os que aceleram a manifestação dos sintomas dos transtornos, como a dieta e eventos estressores. Já os mantenedores, indicam se a doença irá permanecer ou não através do impacto dos sintomas no âmbito fisiológicos e psicológicos (MORGAN et al., 2002).

A maior incidência desses transtornos no público feminino demonstra que tais fatores atingem as mulheres com mais força. Um dos motivos desse cenário é uma imposição corporal feita às mulheres como forma de coerção social.

\section{A estética reacionária}

A luta feminina por espaços de liberdade ao longo da História precisa ser incessante, como bem destacou Beauvoir (1980), para que eles não se percam. Essa busca das mulheres é um movimento de resistência diante das formas instituídas historicamente. $\mathrm{Na}$ sociedade ocidental, a axiomática capitalista emprega o corpo como ferramenta principal de poder sobre a mulher. Um padrão estético se impõe como fato social, cuja existência pode ser comprovada, como demonstrou Durkheim (2004), pela coerção social.

O corpo feminino instrumentalizado como padrão estético se expressa na nomenclatura "mito da beleza". Essa nova forma de controle nasce como resposta ao feminismo e aos direitos conquistados pelas mulheres a partir de então. Direitos como propriedade privada, voto, trabalho e direitos reprodutivos permitiram que as mulheres se libertassem do controle da domesticidade, castidade e passividade. Sendo assim, esse mito vem como um freio a todos esses avanços, trazendo agora o corpo como dispositivo de controle (WOLF, 2019).

Tendo em vista seu objetivo, pode-se perceber que o mito não é sobre as mulheres e sim sobre o poder masculino em determinar seu comportamento. Por conta disso, o mito da beleza não se restringe à aparência, pois está ligado ao modo como as mulheres devem se portar. Daí, ser tratado aqui como uma estética reacionária, que se atualiza em uma série de ideias: a de que a criação dos filhos depende da constante presença materna, de que a respeitabilidade da mulher se pauta em sua não sensibilidade sexual, de uma visão do trabalho feminino que exige das mulheres um investimento maior de horas de trabalho com funções contínuas e trabalhosas. Essas ideias exemplificam as práticas de controle sobre seus corpos (WOLF, 2019).

Além disso, o mito também se estrutura a partir de organizações que se sentem intimidadas pela liberdade das mulheres, organizações controladas por homens, 
que se utilizam da culpa e das incertezas das mulheres sobre a própria libertação para manipulá-las e fazer crescer o mercado das dietas, cosméticos e cirurgias plásticas. Essa manipulação torna o mito palpável e verdadeiro para as mulheres, como se as transformasse na "Donzela de Ferro",

um instrumento de tortura da Alemanha medieval, uma espécie de caixão com a forma de um corpo, que trazia pintados os membros e o rosto de uma jovem bela e sorridente. A pobre vítima era ali encerrada sem pressa. [...] A alucinação moderna que prende as mulheres, ou na qual elas mesmas se prendem, é, da mesma forma, cruel, rígida e adornada de eufemismos (WOLF, 2019, p. 36).

A culpa feminina relacionada com o corpo se dá pela visão de que ele não pertencente à mulher. Desta forma, a noção de um corpo privado dá lugar a uma propriedade que pode ser "alvo de paixão pública" (WOLF, 2019, p. 272). Mostrando então que a imagética da magreza está para além de uma preocupação estética, sendo na verdade uma ferramenta de domínio sobre as mulheres.

A partir dessa questão de domínio, ainda é possível observar como, a partir dele, uma sociedade governada por homens determina quem merece ser bem alimentado ou não, dando à comida um valor social. Os que são considerados inferiores, são relegados a um controle alimentício. Comisso, entende-se que, enquanto as mulheres não puderem participar livremente, assim como os homens, do "banquete que lhes é oferecido" não haverá uma verdadeira igualdade entre gêneros (WOLF, 2019).

Simões-Barbosa e Dantas-Berger (2017) entendem que há um conflito entre a ideia de feminilidade - que nos apresenta uma mulher dócil e pronta para os afazeres domésticos - e a ideia de mulher que tenha características ditas masculinas como a competitividade, competência e força corporal. Nesse embate, a fome feminina é desconsiderada e a diminuição de suas medidas corporais é desprezada em prol de uma descaracterização dos elementos femininos, buscando uma semelhança com os corpos masculinos.

Outro elemento que acompanhou o desenvolvimento do movimento feminista, assim como o do mito, foram as revistas femininas. Tendo em vista a mudança social das mulheres, as revistas passaram a ter mais anúncios sobre alimentos dietéticos e cremes rejuvenescedores do que produtos para casa. Além disso, cresceram as imagens de modelos com um corpo dentro do ideal do mito. Essas reações nada mais são do que uma maneira de mostrar às mulheres que a liberdade $\mathrm{e}$ o poder que elas conquistaram têm um preço: a eterna insatisfação corporal. (WOLF, 2019)

Essa insatisfação corporal crônica entre as mulheres é um mercado lucrativo porque, com a venda de uma imagem física como uma forma de garantir felicidade e beleza, há uma geração de consumo em busca desse ideal. Esse consumismo produz um lucro de bilhões de dólares e faz do Brasil o país que mais faz cirurgias plásticas por motivos estéticos. É notório o poder da mídia na formação de princípios irreais de felicidade, liberdade, autonomia e bem-estar, ditando, concomitantemente, atitudesapropriadas paraaconquista desse fim. (ANDRADE; BOSI, 2003) Em pesquisa realizada pela ENSP/Fiocruz, onde foram analisados os títulos das matérias da revista Capricho, mostra o uso de um conhecimento técnico-científico para responsabilizar a leitora pela própria insatisfação. (SERRA; SANTOS, 2003; WOLF, 2019) Já em Natal/RN, uma pesquisa realizada em farmácias de manipulação percebeu que em 22.158 das notificações que continham fármacos anorexígenos, como anfetamina ou benzodiazepínicos, seriam consumidos, majoritariamente, por mulheres. (SIMÕES-BARBOSA; DANTAS-BERGER, 2017)

Comisso, é importante ressaltar a individualização dessa problemática. Conforme já foi explicitado até aqui, é notório que a desordem na alimentação feminina tem um cunho social. Contudo, pode-se observar a psicologia sendo utilizada para individualizar essa questão, colocando a mulher mais uma vez como responsável sobre um conflito que foi imposto a ela (WOLF, 2019).

\begin{abstract}
As mulheres devem denunciar a anorexia como um mal político perpetrado contra nós por uma ordem social que considera nossa destruição insignificante porque somos o que somos - inferiores. Deveríamos identificar a anorexia como os judeus identificam os campos de extermínio, como os homossexuais identificam a AIDS: como uma desgraça que não é exclusivamente nossa, mas que pertence a uma ordem social desumana (WOLF, 2019, p. 302).
\end{abstract}

A mesma sociedade que pune a mulher por sua emancipação usa essa conquista também como um controle. O discurso de empoderamento usado pelas empresas oferece ao público feminino um poder ilusório, com o objetivo de estimular um ideal de feminilidade inalcançável que alimenta uma indústria de dietas e de cosméticos. A partir disso pode-se observar uma dedicação das mulheres a disciplinar seus corpos aos métodos de transformação e aperfeiçoamento corporal. (SIMÕES-BARBOSA; DANTAS-BERGER, 2017)

Juntamente a isso, cria-se a ideia do corpo maleável. Um corpo capaz de ser moldado a partir de procedimentos estéticos, alimentação restritiva ou exercícios físicos, desconsiderando os aspectos genéticos. Tal corpo, ao se tornar magro, daria às mulheres a imagem de beleza, poder e mobilidade social, o que produz um campo contraditório, uma vez que, por intermédio dos meios de comunicação, as indústrias alimentícias comercializam produtos altamente calóricos ao mesmo tempo em que exigem um corpo magro (ANDRADE; BOSI, 2003; VASCONCELOS; 
SUDO; SUDO, 2004).

Observa-se então que o machismo e a misoginia que estão enraizados na sociedade têm um grande papel de perpetuação de um padrão de beleza inatingível, não para um fim estético, mas com a função de controle social. Essa imposição corporal é causadora de um enorme sofrimento, tanto físico como psicológico, que afeta a autoestima das mulheres - independente da faixa etária - e gera um movimento de ódio ao próprio corpo que acarreta as práticas alimentares disfuncionais já citadas.

\section{Considerações Finais}

O corpo é o começo e o fim do ser humano, por isso é tão importante entendê-lo e controlá-lo. Além de uma ferramenta potente de conexão e afetamento com o outro, o corpo também é o centro das práticas de poder. Tais práticas são infligidas por diversas áreas do conhecimento desde a arte até a medicina. O corpo é assujeitado a normas que o impõe o que vestir, o que gostar, o que fazer e, quando se é um corpo feminino, que peso ter.

Essas normas e práticas de controle afetam os hábitos alimentares das mulheres, fazendo com que elas desenvolvam uma relação não saudável com a comida. Através de restrição na ingesta de alimento, medicamentos, vômitos autoinduzidos e exercícios extenuantes que são iniciados os transtornos alimentares. Aqui foram explicitadas a bulimia e a anorexia, contudo, é notório que mesmo as mulheres que não apresentam tais transtornos demonstram uma insatisfação corporal que as levam a negligenciar sua alimentação. Tendo os transtornos alimentares a maior letalidade dentre os transtornos mentais, é preocupante a falta de discussão sobre o tema, suas causas e seus efeitos.

Pensando as causas, deve-se levarem consideração todo o contexto social que incentiva as mulheres a se colocarem nessa posição. O mito da beleza, como já citado, atua punindo e controlando as mulheres por ousarem conquistar a liberdade antes só oferecida aos homens. Sua principal ferramenta de coerção é a beleza, que mercantiliza uma ideia de sucesso e felicidade, e a partir dela aprisiona-se a mulher em seu próprio corpo.

Retomando a pergunta do início deste artigo e analisando tudo que foi exposto, pode-se perceber que os efeitos de tais práticas no corpo feminino são palpáveis e perceptíveis uma vez que muitas mulheres são afetadas por esses discursos que as definem por seus corpos ao mesmo tempo em que minimizam os impactos das conquistas femininas. É também notório o quão nocivo são essas normas de controle, sendo muitas vezes sutis e pouco agressivas, mas ainda assim que colocam a mulher em um lugar de sujeição ao domínio masculino.

\section{Referências}

ANDRADE, S. S. Saúde e beleza do corpo feminino- algumas representações no Brasil do século XX. Movimento, Rio Grande do Sul, v. 9, n. 1, p. 119143, jan/abril, 2003.

ANDRADE, A.; BOSI, M. L. M. Mídia e subjetividade: impacto no comportamento alimentar feminino. Revista Nutrição, Campinas, SP, v. 16, n. 1, p. $117-125, \mathrm{jan} / \mathrm{mar}, 2003$

APPOLINÁRIO, J. C.; CLAUDINO, A. M. Transtornos alimentares. Revista Brasileira de Psiquiatria, v. 22, supl. 2, p. 28-31, 2000.

ARTAUD, A. O teatro e seu duplo. São Paulo: Martins Fontes, 1988.

ASSOCIAÇÃO AMERICANA DE PSIQUIATRIA. Manual de Diagnóstico e Estatística de Transtornos Mentais. ed. 5, (DSM-V). Arlington, VA: American Psychiatric Association, 2014.

BEAUVOIR, S. O segundo sexo 1: fatos e mitos. Rio de Janeiro: Nova Fronteira, 1980.

BRASIL. Ministério da Educação. Hospitais oferecem tratamento para transtornos alimentares. Brasília: MS, abr 2019. Disponível em: http://portal. mec.gov.br/component/content/article/212-noticias/educacao-superior$1690610854 / 75111$-hospitais-oferecem-tratamento-para-transtornosalimentares?Itemid=164 Acesso em 13 jan 2020.

CORDÁS, T. A.; CLAUDINO, A. M. Transtornos alimentares: fundamentos históricos. Revista Brasileira de Psiquiatria, v. 24, supl. 3, p. 3-6, 2002.

DELEUZE, G.; GUATTARI, F. O que é a filosofia. São Paulo. Ed. 34, 1999.

DURKHEIM, E. As regras do método sociológico. Petrópolis: Vozes, 2004.

ESPINOSA, B. Ética: demonstrada à maneira dos geômetras. São Paulo: Martin Claret, 2002

FOUCAULT, M. Vigiar e punir: nascimento da prisão. 36. ed. Petrópolis: Vozes, 2009.

HAY, P. J. Epidemiologia dos transtornos alimentares: estado atual e desenvolvimentos futuros. Rev. Bras. Psiquiatr., São Paulo, v. 24, supl. 3, p. 13 17, Dez. 2002. Disponível em: <http://www.scielo.br/scielo.php?script=sci arttext\&pid $=$ S1516-44462002000700004\&lng $=$ en\&nrm $=$ iso $>$. Acesso em 02 jan. 2020

LÉVY, P. O que é o virtual. São Paulo: Ed. 34, 1996.

MORGAN, C. M.; VECCHIATTI, I. R.; NEGRÃO, A. B. Etiologia dos transtornos alimentares: aspectos biológicos, psicológicos e sócio-culturais. Revista Brasileira de Psiquiatria, v. 24, supl. 3, p. 18-23, 2002.

OLIVEIRA, L. L.; HUTZ, C. S. Transtornos alimentares: o papel dos aspectos culturais no mundo contemporâneo. Psicologia em Estudo, Maringá, v.15, n. 3 , p. $575-582$, jul./set, 2010.

POE, E. A. A máscara da morte rubra. In: Histórias extraordinárias. São Paulo: Companhia das Letras, 2018.

SERRA, G. M. A.; SANTOS, E. M. Saúde e mídia na construção da obesidade e do corpo perfeito. Ciência e Saúde Coletiva, v. 8. n. 3, p.691-701, 2003.

SIMÕES-BARBOSA, R. H.; DANTAS-BERGER, S. M. Abuso de drogas e transtornos alimentares em mulheres: sintomas de um mal-estar de gênero? Cadernos de Saúde Pública, v. 33, n. 1, 2017.

UM CÃO ANDALUZ. Direção: Luis Buñuel. França, 1929.

VASCONCELOS, N. A.; SUDO, I.; SUDO, N. Um peso na alma: o corpo gordo e a mídia. Revista Mal-Estar e Subjetividade, Fortaleza, v. 4, n. 1, p. 65-93, mar, 2004.

WOLF, N. O mito da beleza: como as imagens de beleza são usadas contra as mulheres. 6 ed, Rio de Janeiro 